\title{
Challenges in hydrogen storage
}

\author{
F. Schüth \\ Max-Planck-Institut für Kohlenforschung, 45470 Mülheim, Germany
}

\begin{abstract}
Hydrogen is one possible medium for energy storage and transportation in an era beyond oil. Hydrogen appears to be especially promising in connection with electricity generation in polymer electrolyte membrane (PEM) fuel cells in cars. However, before such technologies can be implemented on a larger scale, satisfactory solutions for on-board storage of hydrogen are required. This is a difficult task due to the low volumetric and gravimetric storage density on a systems level which can be achieved so far. Possibilities include cryogenic storage as liquid hydrogen, high pressure storage at $70 \mathrm{MPa}$, (cryo)adsorptive storage, or various chemical methods of binding and releasing hydrogen. This survey discusses the different options and the associated advantages and disadvantages.
\end{abstract}

\section{Introduction}

Hydrocarbons, especially oil and gas, are the backbone of our economy and our energy infrastructure. However, with dwindling reserves and decreasing new discoveries of large oil and gas fields, it is crucial to consider other options for our energy system. Hydrocarbons have been a source of energy for our societies, but often forgotten is their role in long term energy storage and transportation. Our energy future will undoubtedly become more "electric", but it is very difficult to store electricity in large amounts for long times. Therefore, also a future energy system will need a material for efficient energy storage, especially since most renewable energy sources deliver energy with rather high fluctuations over shorter and longer time periods (day/night, summer/winter). Ideal materials for energy storage have to meet numerous requirements. Amongst others, they have to be efficient, i.e. storing and release of energy should not be associated with high losses, they should be safe and clean, no losses should occur with time of storage, a high volumetric and gravimetric storage density should be possible, and the costs should be reasonably low. Considering all these-partly competing-requirements, one of the best solutions seems to be hydrogen. The energy density of hydrogen exceeds that of any other chemical storage medium with a value of $120 \mathrm{MJ} \mathrm{kg}^{-1}$. It can be generated by thermal processes or by electrolysis from the all abundant water, and converted back to electricity directly in fuel cells, albeit under some loss of energy. Hydrogen is non-toxic, the reaction product upon releasing the stored energy is just water. With respect to safety, one certainly has to take into account the flammability of hydrogen and its explosiveness in mixture with air within wide limits. However, hydrogen can be handled safely under industrial conditions, and numerous experimental hydrogen filling stations for cars are operating in many countries without problems. In considering alternatives to our current infrastructure, one should keep in mind that also hydrocarbons are not without danger: also they form explosive mixtures with air (otherwise no motor would be running), and the danger of environmental pollution due to oil spills can certainly not be neglected. We have just become more acquainted with these dangers over more than one century, during which this technology has been in place, and novel systems are competing against this everyday acquaintance and this commonly accepted risk.

While hydrogen appears to be a viable alternative to hydrocarbons as a backbone of our energy infrastructure, there are severe challenges to be met still. One of the biggest is certainly 
the storage of hydrogen in moderate quantities, as would be needed for operation of a fuel cell driven car. In order to achieve approximately the same driving range as conventional cars, one would need to store on the order to $5-10 \mathrm{~kg}$ of hydrogen on board which poses substantial challenges. Storage of larger amounts of hydrogen is less of a problem, although also not simple. Nevertheless, if driving ranges as with internal combustion engines are the target, batteries are most probably not a viable alternative to hydrogen in combination with a fuel cell, since the energy density of batteries is about an order of magnitude smaller, as illustrated in Fig. 1. In the following, different options for storage of hydrogen will be discussed, while at the end the possibilities will be compared and discussed taking into account a systems perspective, since energy technologies are never isolated, but have to be discussed in connection with the overall energy infrastructure. No complete review over the literature will be given, but just the major trends and developments will be highlighted. For a more complete literature survey, readers are referred to several recent reviews, covering broadly the topic of hydrogen storage [1-4].

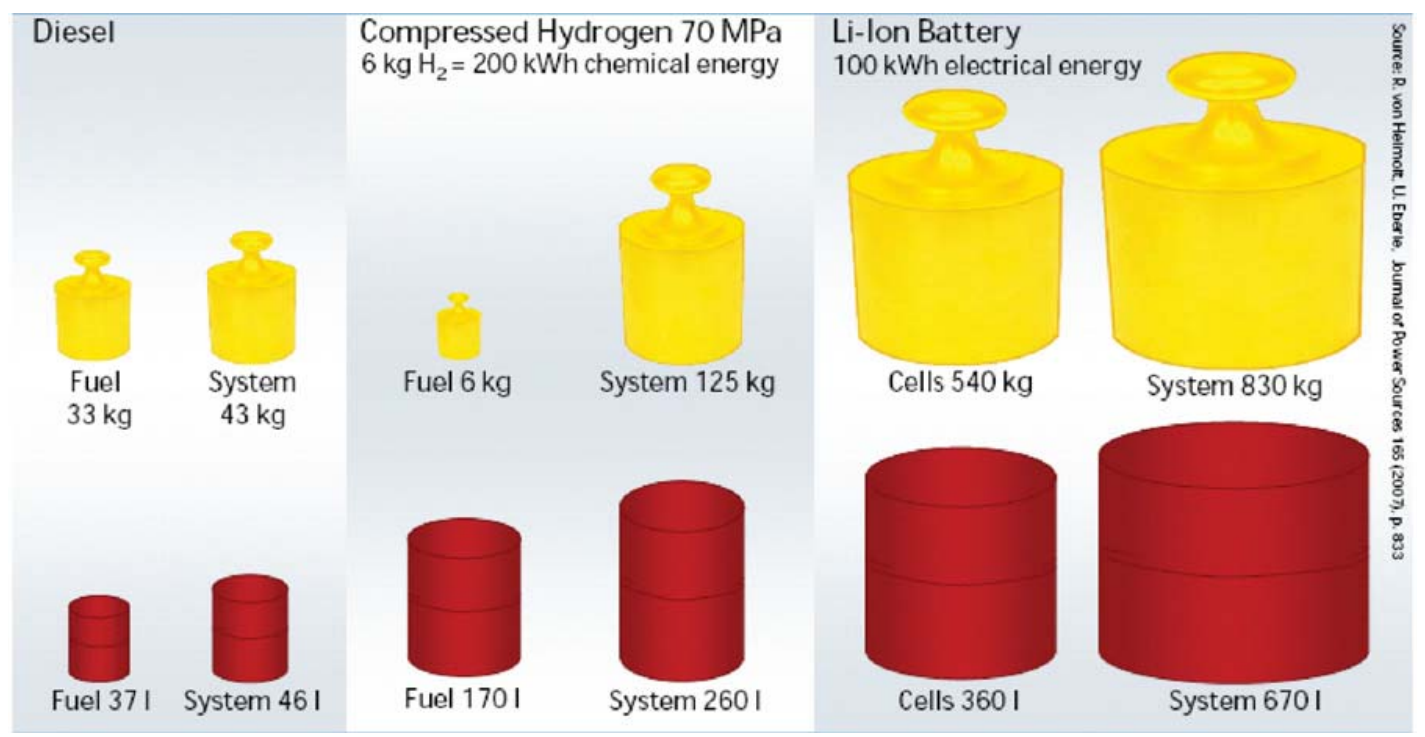

Fig. 1. Comparison of weight and volume of diesel fuel, hydrogen, and a Li-ion battery pack for equivalent driving ranges (from ref. [5]).

\section{Compressed gaseous hydrogen (CGH2)}

In form of the gas at atmospheric pressure, the volumetric storage density is much too low for any practical purpose. It is thus clear that only gaseous hydrogen at high pressure can be considered for on-board storage in a car. The state-of-the-art system which is used nowadays in several prototype vehicles of different car manufacturers is a $70 \mathrm{MPa}$ composite vessel (approximately $37 \mathrm{~kg} \mathrm{H}_{2} \mathrm{~m}^{-3}$ ). Substantially lower pressures result in an insufficient volumetric storage density. Increasing the pressure further does not appear to be useful, since at such high pressures the deviations from the ideal gas law are quite noticeable (at $70 \mathrm{MPa}$ one would calculate a density of about $57 \mathrm{~kg} \mathrm{H}_{2} \mathrm{~m}^{-3}$ from the ideal gas law, compared to the $37 \mathrm{~kg} \mathrm{H}_{2} \mathrm{~m}^{-3}$ achieved in practice) and the storage density increases much lower than linearly with pressure in this range, so that the small increase in storage density is not justified by the increasing demands placed on the vessel, if the pressure would be increased further [3].

The vessel itself is a composite system with an inner liner consisting of a high density polymer as impenetrable barrier for hydrogen, a carbon-fiber/polymer composite shell to withstand the pressure, and an outer layer of polymer to provide impact resistance [6]. In order to withstand high pressure at minimal weight, a spherical shape would be optimal. However, this would cause insurmountable problems in packaging in a car, and thus the cylindrical shape with two hemispherical endcaps is technically used. 
One should keep in mind that energy is required for the compression of the hydrogen. The lower limit for the energy required is estimated by integrating the ideal gas law under the assumption of isothermal compression. This calculation gives a value of about $8 \mathrm{MJ} \mathrm{kg}^{-1} \mathrm{H}_{2}$ for compression to $70 \mathrm{MPa}$. In practice, however, the compression is not isothermal and in addition, mechanical losses in the compressor unit have to be taken into account. This leads to more than twice the value calculated for the ideal case, i.e. approximately $18 \mathrm{MJ} \mathrm{kg}^{-1} \mathrm{H}_{2}$ [4]. This corresponds to about $15 \%$ of the energy content of the hydrogen, based on the lower heating value, i.e. the combustion enthalpy calculated for the production of gaseous water. In principle, it should be possible to recover part of this compression energy on board of the car, since the hydrogen in the fuel cell is needed at a pressure only slightly above atmospheric pressure. However, presently no weight and space economic solutions for recovering the compression energy appear to be available, so that this part of the energy stored in the tank has to be considered as lost.

CGH2 is the present day benchmark technology for on-board hydrogen storage. In spite of the disadvantages, such as low volumetric storage densities, the requirement to pack cylindrical vessels, and the cost of the tanks, this technology outperforms all other alternatives, since the gravimetric storage densities are reasonable, there are no losses during storage, the start-up is instantaneous, and no heat exchangers are required.

\section{Liquid hydrogen}

Hydrogen becomes liquid at about $-253^{\circ} \mathrm{C}$ at atmospheric pressure and can be stored and transported in this state. A major part of the technical hydrogen is in fact delivered in liquefied form by trailers carrying more than three tons of liquefied hydrogen [7]. Unfortunately for hydrogen storage in cars, the density of liquid hydrogen is rather low at only about $0.071 \mathrm{~g} \mathrm{~cm}^{-3}$. In addition, the difficulties to avoid evaporation losses increase with decreasing amount of hydrogen to be stored, since the surface, via which heat flows into the vessel, decreases only with the square of the system size, while the volume, i.e. the total amount of hydrogen stored, decreases with the cube of the system size. This means that the relative importance of heat flow into the vessel is higher for smaller systems. Thus, while evaporation losses can largely be ignored for big trailers carrying three tons of hydrogen, this is rather different for tanks with a capacity of only some kilograms. Some heat influx can be tolerated, since a liquid hydrogen tank can hold a pressure of about $1 \mathrm{MPa}$. The first hydrogen evaporated thus only leads to a pressure increase in the vessel, but not to loss of hydrogen. However, as soon as the threshold value is reached, a valve has to be opened to release the excess pressure. In ideal cases, this period until which no loss occurs, can last up to several days.

Additional evaporation losses occur during refilling, since the transfer line from the reservoir to the tank has to be cooled down to $-253^{\circ} \mathrm{C}$. While manufacturers of equipment have found solutions to minimize evaporation losses during filling, for instance by using coaxial cryogenic connectors which avoid cold valves [7], evaporation can not completely be suppressed and thus these additional losses have to be accepted.

Overall, the tank systems for liquid hydrogen are rather complex. In order to minimize the heat influx, the tanks are vacuum insulated and, in addition, contain a series of radiation shields (up to 40 individual layers) which are difficult to assemble, especially in the domes of the vessels and wherever there are feedthroughs. While such tanks can be produced, the costs associated with their manufacture are substantial.

Finally, a disadvantage of liquefied hydrogen is also the energy consumption for the liquefaction itself. It costs approximately $30 \%$ of the energy content of the hydrogen and is therefore substantially worse compared to CGH2. Recovery of the liquefaction energy during operation also does not appear to be possible. Although this high energy consumption for liquefaction appears to be a severe disadvantage, this may not be so bad, if the integration in an overall system is considered. One should bear in mind that the hydrogen needs to be delivered to the filling station or generated on site. If it is delivered to the station, it is probably in the liquefied state, and thus the liquefaction energy needs to be expended anyway, so that it is not necessarily a disadvantage of the storage option on board, but an overall systems disadvantage of an infrastructure based on liquefied hydrogen. 
Nevertheless, due to the many shortfalls of liquid hydrogen storage on board of vehicles, most car manufacturers seem to pursue this storage option only with low priority.

\section{Adsorptive hydrogen storage options}

Interaction of gases with a surface leads to adsorption. By this process, an adsorbate is formed in which the density of the gas species is much higher than in the gaseous state, provided that the interaction energy is sufficiently high. Thus, if adsorbents with a high specific surface area are offered, relatively high gravimetric and volumetric storage densities for the gas under consideration might be achieved. Unfortunately, for hydrogen the interaction energies with most surfaces are only moderate, on the order of $5 \mathrm{~kJ} \mathrm{~mol}^{-1} \mathrm{H}_{2}$. At such low interaction energies, significant amounts of hydrogen can only be stored at low temperatures and high pressures. The temperatures do not need to be as low as in liquid hydrogen storage, liquid nitrogen temperature $\left(-196^{\circ} \mathrm{C}\right)$ is sufficient to reach appreciable amounts of hydrogen adsorbed at pressures of some MPa.

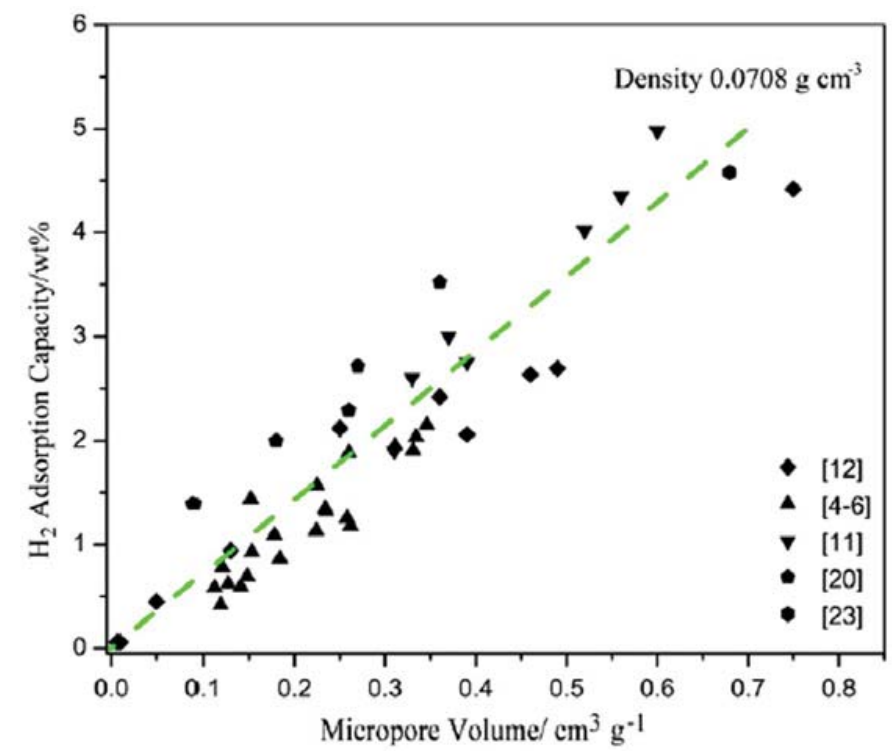

Fig. 2. $\mathrm{H}_{2}$ adsorption capacity vs. micropore volume for different carbon samples. The line is the expected amount adsorbed if the volume were filled with liquid $\mathrm{H}_{2}$ (from ref. [8]).

Various different adsorbents have been explored as potential hydrogen storage materials, among them various zeolites, many different types of carbon, including activated carbons and different carbon nanotubes, or so called metal organic frameworks (MOFs). Best seem to be such materials which have a high specific surface area and pores in the nanometer size range, since in such small pores the adsorption enthalpies are lower than in bigger pores. For many different carbon materials, the limiting adsorption capacities seem to fall on a common line, if the amount adsorbed is plotted against the micropore volume (Fig. 2) [8].

Similar correlations, although with slightly larger scatter, can be found if the amounts adsorbed are plotted against specific surface areas of different carbons, with proportionality constants around $1.3 \mathrm{~g} \mathrm{~m}^{-2}$ [9]. Considering the fact that it will be very difficult to produce carbons with higher micropore volumes or higher specific surface areas than the ones already tested, it is difficult to foresee a substantial further increase in the adsorption capacity of carbon based adsorbents. In addition, one has to take into account, that with such a system based an adsorptive storage, one has to accept the worst of three worlds to achieve storage capacities on a materials basis which come close to targets: it is necessary to use an adsorbent, which means 
extra weight and space requirements, it is necessary to cool the system down to liquid nitrogen temperature, requiring a complex cryogenic systems, even if the demands are less stringent than for a liquid hydrogen vessel, and finally, also pressures of several MPa are necessary, creating the need for a sufficiently stable tank.

There is one class of materials, for which there still seems to be potential for improvement of the storage properties, i.e. the so-called MOFs (hydrogen sorption in MOFs has been reviewed recently by Dinca and Long [10]). MOFs are porous coordination polymers. They consist of inorganic clusters, mostly oxo-clusters of transition metals, which form the vertices in three-dimensional networks, and these vertices are connected by organic linker molecules. The different motifs of connectivity of vertices and linkers can result in a large variety of topologies of the resulting porous solids (Fig. 3).

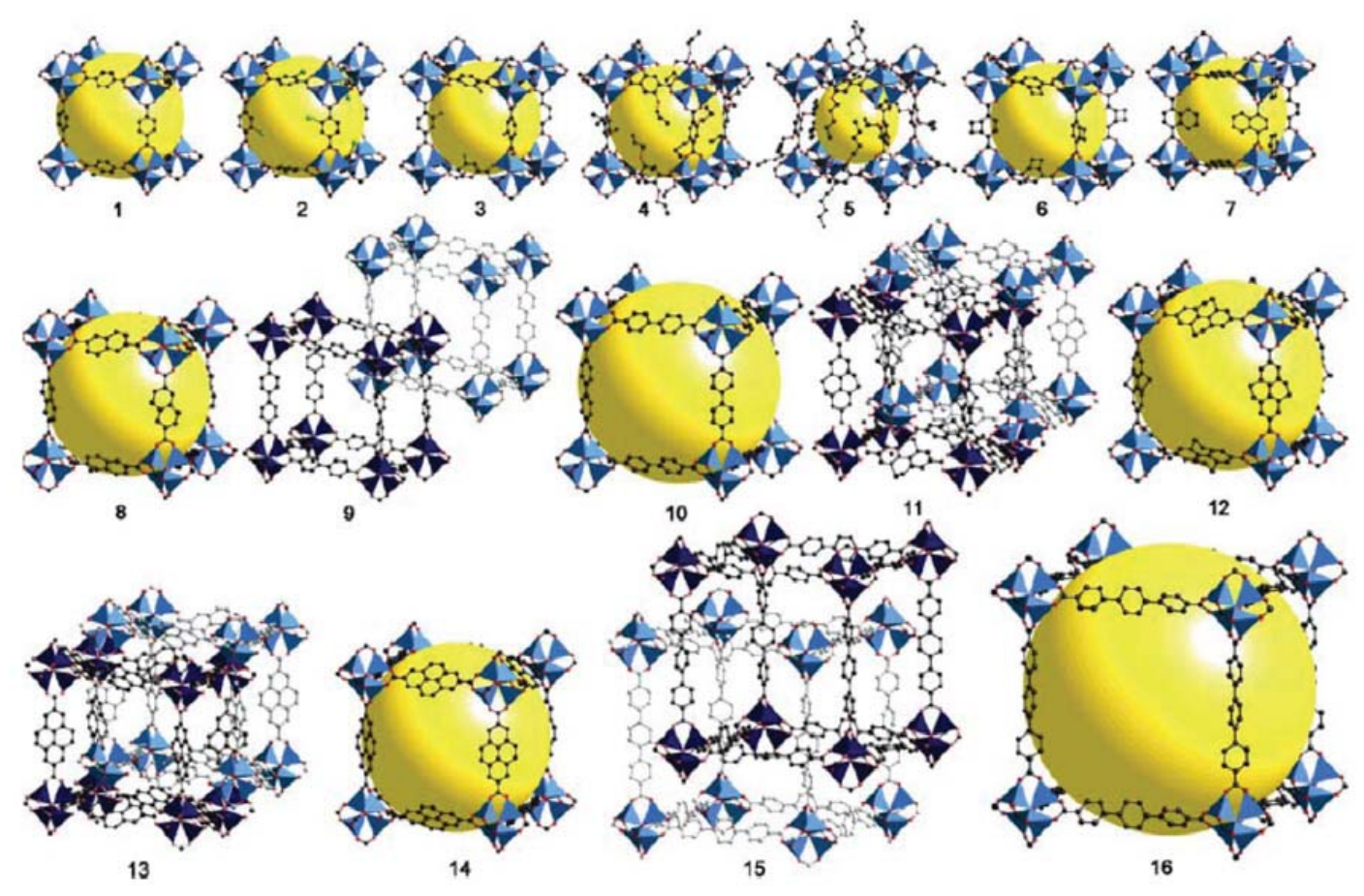

Fig. 3. A series of different MOFs prepared with different linkers, but based on the same vertices, which consist of $\mathrm{Zn}_{4} \mathrm{O}$-clusters, in which the $\mathrm{Zn}$-atoms are additionally coordinated by carboxylate groups from the linker (from ref. [11]).

The flexibility of this synthetic concept allows for tunability of the materials properties over wide parameter ranges. The nature of the vertex atoms can be tuned, the properties of the linkers can be adapted, and thus this class of materials raised high hopes for the development of novel hydrogen storage materials. For the so called IRMOF-177, capacities exceeding 7 wt.\% have been reported for $-196^{\circ} \mathrm{C}$ and a pressure of $6 \mathrm{MPa}$ [12].

The goal of current research in this field is an increase in the adsorption enthalpies for hydrogen in such materials. Increased adsorption enthalpies would mean increased temperatures at which reversible adsorption/desorption would be possible. From thermodynamic considerations one can estimate that for an adsorption system operating around room temperature an adsorption enthalpy around $15 \mathrm{~kJ} \mathrm{~mol}^{-1}$ would be necessary [13], about two to three times as much as normally found for adsorption on microporous materials. The strategies to achieve this goal mainly rely on the introduction of coordinatively unsaturated metal centers in MOFs on which a localized, strong adsorption of $\mathrm{H}_{2}$ could occur [10]. However, the high total adsorption capacities of MOFs are achieved due to the relatively unspecific adsorption on their 
high surface areas. If localized exposed metal sites are introduced, this may lead to increased adsorption enthalpy, however, most probably this will be on expense on adsorbed volume, so that it remains to be seen whether both target properties can be optimized simultaneously.

There is some additional promise in adsorption on so-called covalent organic frameworks, in which purely organic building blocks are connected in a fashion to result in highly porous materials. Molecular dynamics simulations of the adsorption of hydrogen in such materials predict adsorption capacities up to $10 \mathrm{wt} \%$ [14]. However, only for a low capacity material with about $3 \mathrm{wt} . \%$ has this theoretical prediction been confirmed experimentally, and it is at present unclear whether the very high predicted values can be realized in practice.

\section{Storage in hydrides}

Since the methods for hydrogen storage discussed so far all suffer from different shortcomings, the use of chemical methods for storage has been advocated since the early days of hydrogen storage research. Hydrides can be discriminated according to their bonding situation. There are metallic hydrides, which are typically formed with metals from the transition elements, there are salt-like hydrides, which are mostly binary compounds of the early main group elements, i.e. the alkali and alkaline earth elements and hydrogen, and there are complex hydrides, which consist of a metal cation and a complex, hydrogen containing anion, such as the $\mathrm{AlH}_{4}^{-}$or the $\mathrm{BH}_{4}^{-}$anion. In addition, there are covalent element hydrogen compounds, such as $\mathrm{NH}_{3}$ or $\mathrm{CH}_{4}$.

In general, there are two possible pathways in which a hydride can be used as hydrogen storage material: (i) the hydrogen is released in a hydrolytic reaction, i.e. by reaction with water, in which often also the hydrogen from the water can be used, or (ii) the hydrogen is released reversibly, i.e. by heating or reduction of the pressure the hydrogen is liberated, while increase of pressure or decrease of temperature leads to readsorption of the hydrogen. The second pathway is by far preferable, since in all hydrolytic systems, the spent hydride solution - which is then typically present in form of an oxide or hydroxide slurry - needs to be shipped back to the factory in order to be recycled. It should also be noted that hydrogen can only be released from a hydrogen containing compound by a hydrolytic pathway, if the hydrogen is at least partially negatively charged in the compound. Otherwise no reaction with water to release hydrogen takes place. Thus, compounds such as $\mathrm{NH}_{3}, \mathrm{CH}_{4}$ or $\mathrm{H}_{2} \mathrm{~S}$ can not be used for hydrolytic hydrogen generation.

\subsection{Hydrolytic systems}

The most advanced system for hydrolytic hydrogen generation from a hydride is certainly the one introduced by Millenium Cell, i.e. the system based on an alkaline solution of $\mathrm{NaBH}_{4}$ which is schematically sketched in Fig. $4 . \mathrm{NaBH}_{4}$ in absence of a catalyst is reasonably stable in alkaline aqueous solution. However, when contacted with a suitable catalyst, such as ruthenium compounds, the hydrogen is released easily, a fact which is known for more than 50 years [15]. The product of the reaction, an aqeous slurry of $\mathrm{NaBO}_{2}$, has to be collected and shipped back to a plant to be regenerated.

Due to many problems associated with this hydrolytic system, the development of $\mathrm{NaBH}_{4}$ based hydrolytic storage systems for application in cars seems to have been completely discontinued by all car manufacturers, although a prototype vehicle on the basis of a Chrysler Voyager car has been in operation.

A related system, however, is receiving a lot of attention recently, at least in research. Boron-nitrogen compounds can in principle contain a lot of hydrogen [16]. The simple borazane, $\mathrm{BH}_{3} \mathrm{NH}_{3}$ contains close to $20 \%$ of hydrogen, which can partly be released at $130{ }^{\circ} \mathrm{C}$ to result in the formation of borazine. This release corresponds to $14 \mathrm{wt} . \%$ storage capacity. However, the thermal release of hydrogen is irreversible, and borazine can not be rehydrogenated to result in the formation of borazane. Alternatively, the hydrogen from boron-nitrogen compounds can be liberated by a hydrolysis process. A suitable compound for hydrolytic hydrogen generation is ammonia triborane $\mathrm{NH}_{3} \mathrm{~B}_{3} \mathrm{H}_{7}$ which releases $8 \mathrm{~mol}$ of $\mathrm{H}_{2}$ upon reaction with water. The solubility is about $33 \%$ in water, and the hydrolysis reaction is catalyzed by noble metal 


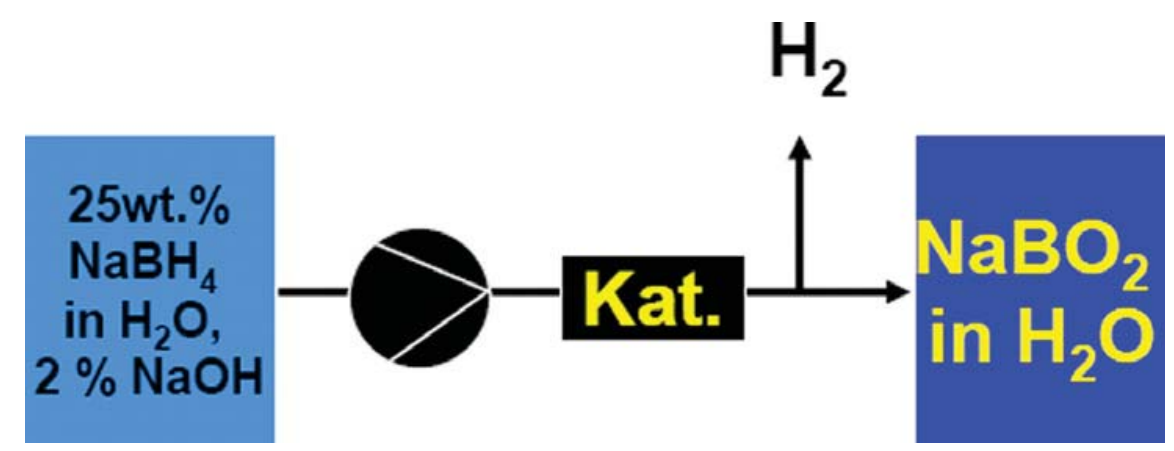

Fig. 4. Schematic description of a hydrolytic hydrogen storage system based on an alkaline aqueous solution of $\mathrm{NaBH}_{4}$.

catalysts. The system thus very much resembles the $\mathrm{NaBH}_{4}$ system introduced by Millenium Cell. However, it has similar disadvantages, such as the need to regenerate the material after shipping it back to a plant. The storage capacity is higher than for sodium boronhydride. However, it carries the additional disadvantage that ammonia may be released which would poison the acidic membrane of the fuel cell and thus has to be efficiently removed from the product gas.

There are a number of other systems which can release hydrogen by a hydrolytic process. However, they all seem to be inferior to the systems discussed above, and thus it is not expected that they will enter practical applications.

\subsection{Reversible hydrides}

In order for a hydride to be useful for hydrogen storage in reversible manner, it has to meet a number of requirements. Firstly, the storage capacity has to be sufficiently high, i.e. for a reversible hydride, which can be re- and dehydrogenated at moderate temperature and pressure a capacity of about 7 wt.\% seems to be necessary. Secondly, the system needs to have thermodynamic parameters which make it useful in the temperature range of the target application. PEM fuel cells operate at temperatures of $80-90^{\circ} \mathrm{C}$, and in order to avoid additional heating systems, this temperature should be sufficient to reach an equilibrium pressure of around $0.5 \mathrm{MPa}$ of hydrogen which means that $\Delta \mathrm{G}_{R}^{0}$ is around $0 \mathrm{~kJ} \mathrm{~mol}^{-1}$ at room temperature. Thirdly, even if this thermodynamic boundary condition is met, the kinetics of de- and rehydrogenation still need to be sufficiently fast to allow on-board regeneration of the hydride and a sufficient hydrogen flow during operation.

Figure 5 gives a survey over the materials landscape of different hydrides in terms of their gravimetric and volumetric storage density. For practical applications one has to keep in mind that these are the parameters of the material only. However, decisive is the system storage density, i.e. including container, flow management system, heat exchangers, etc., so that systems storage densities will be appreciably lower than suggested by Fig. 5 .

As one can see from Fig. 5, the classical metallic hydrides all have high volumetric storage capacities which are very desirable, but lack in gravimetric capacities. Thus, all these compounds, such as $\mathrm{Mg}_{2} \mathrm{Fe}, \mathrm{LaNi}_{5}$ or $\mathrm{FeTi}$, are not useful for hydrogen storage in cars. Interesting capacities are only reached for some of the salt-like hydrides, such as $\mathrm{MgH}_{2}$, or the complex hydrides, as given in the figure. However, even these are mostly not directly suitable for hydrogen storage purposes in cars, since their thermodynamic properties do not allow discharging and charging at moderate pressures at the temperature level of the PEM fuel cell. For instance, $\mathrm{MgH}_{2}$, which has a storage capacity of $7.7 \mathrm{wt} . \%$, is available at low cost, and shows good reversibility, would in principle be ideal. However, the thermodynamics of the system is such that it would need to operate at $300^{\circ} \mathrm{C}$, which would require additional heating systems. This makes the overall system rather unattractive and unsuitable for on-board hydrogen storage. 


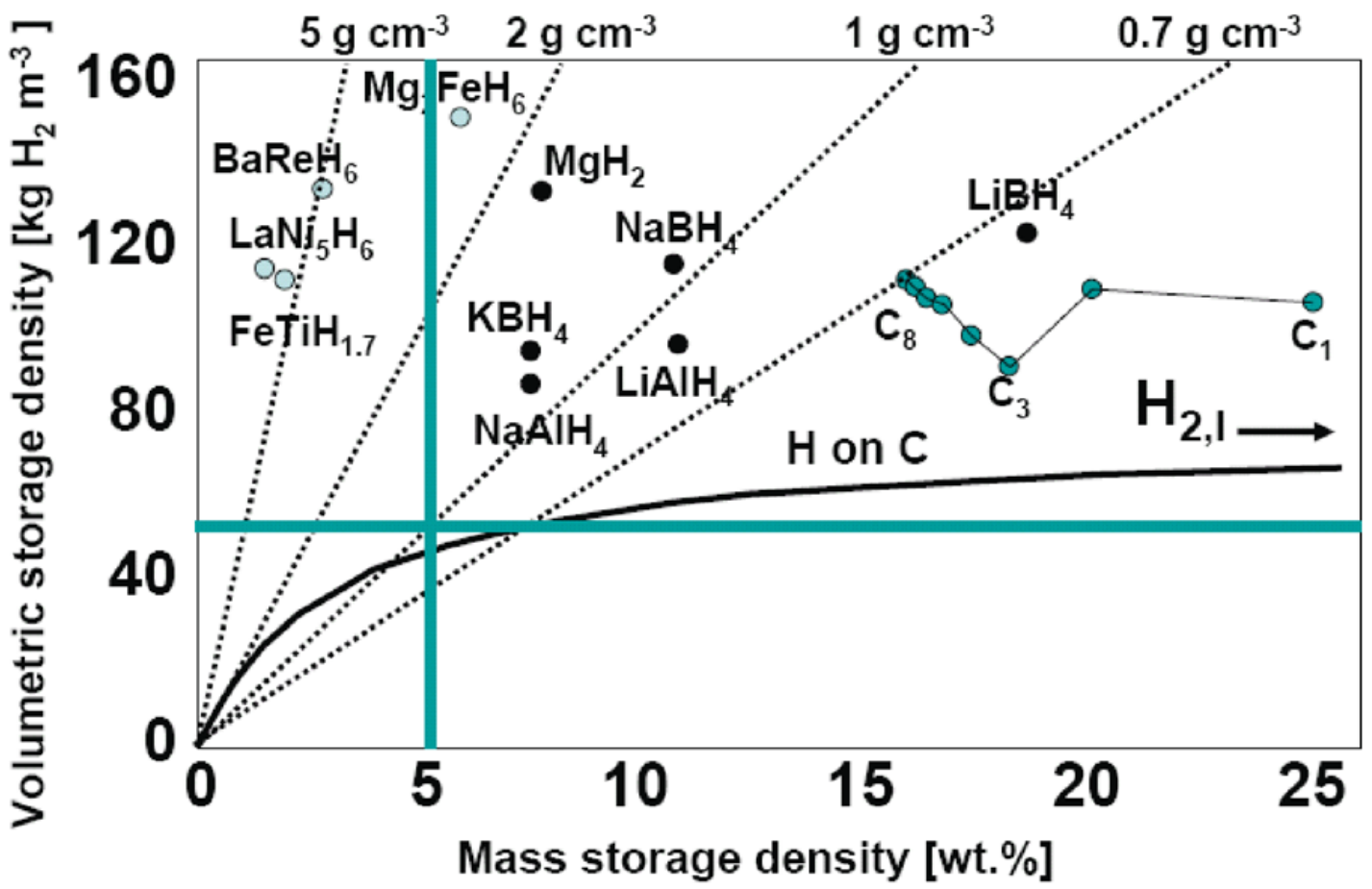

Fig. 5. Materials landscape of different hydrides. Plotted are volumetric and gravimetric storage densities. For practical application, system capacities above $5 \%$ both in terms of volumetric and gravimetric density should be targeted at, which means that only compounds well in the upper right segment can be considered. In addition, it should be noted that capacities are calculated for full dehydrogenation, which can not be achieved for all compounds under practical conditions. Replotted after ref. [2].

The only hydride in the region of interesting storage capacities with suitable thermodynamic properties known so far is $\mathrm{NaAlH}_{4}$. $\mathrm{NaAlH}_{4}$ decomposes in two steps according to eq. (1) and (2):

$$
\begin{gathered}
3 \mathrm{NaAlH}_{4} \leftrightarrow \mathrm{Na}_{3} \mathrm{AlH}_{6}+2 \mathrm{Al}+3 \mathrm{H}_{2} \\
\mathrm{Na}_{3} \mathrm{AlH}_{6} \leftrightarrow 3 \mathrm{NaH}+\mathrm{Al}+1.5 \mathrm{H}_{2}
\end{gathered}
$$

corresponding to an overall storage capacity of $5.5 \mathrm{wt} . \%$. The first decomposition step yields an equilibrium $\mathrm{H}_{2}$ pressure of $0.1 \mathrm{MPa}$ at approximately $30^{\circ} \mathrm{C}$ and releases $3.7 \mathrm{wt} . \%$ of hydrogen, the second step releases another $1.9 \mathrm{wt} . \%$ and has an equilibrium pressure of $0.1 \mathrm{MPa}$ at $130{ }^{\circ} \mathrm{C}$. In principle, also the hydrogen from the $\mathrm{NaH}$ could be released, but this requires temperatures exceeding $500^{\circ} \mathrm{C}$ which is technically not useful.

However, this system, like many other hydrides, suffers from a severe shortcoming. The kinetics of both decomposition steps are so sluggish that under practically relevant conditions neither sufficiently rapid release of hydrogen nor re-hydrogenation are even close to being fast enough. It was thus a major breakthrough, when Bogdanovič and Schwickardi discovered that both reactions can be strongly accelerated by doping the $\mathrm{NaAlH}_{4}$ with transition metal compounds, most notably with titanium species [17]. This system has up to now been studied very intensively, and both improved methods of doping [18] and improved catalysts have been developed $[19,20]$. The method of choice for the doping reaction is ball milling, the best catalyst described so far is scandium (which, however, would probably be too expensive for large scale application). Direct synthesis of the compound, from $\mathrm{NaH}, \mathrm{Al}$-powder, $\mathrm{ScCl}_{3}$ by reactive ball milling under hydrogen pressure, gives a material, for which rehydrogenation is possible in less than five minutes, which would be acceptable for practical applications. 
Due to the complexity of the system, it has taken some time to clarify the state of the titanium catalyst and to obtain indications on the mode of action (scandium may be similar in these respects, but there are no data on this system as yet). By now it is clear that the titanium is zerovalent in all stages of the dehydrogenation/rehydrogenation cycle. Moreover, the first coordination sphere resembles a Ti-Al-alloy, most closely the $\mathrm{TiAl}_{3}$ phase, as has been revealed by X-ray absorption spectroscopy [21-23]. Recent data suggest that titanium species in the surface are the most effective ones for the hydrogen uptake and release [24]. The catalyst has at least two effects: (i) it must facilitate the mass transfer and (ii) it activates the hydrogen by dissociation on the surface of the material [25]. The latter point has clearly been proven by hydrogen/deuterium scrambling experiments, while the first point can be concluded from the kinetics, but experimental data are still scarce. It is clear, though, that a mobile, aluminium containing species is formed during rehydrogenation, possibly an alane species [26].

However, as interesting as $\mathrm{NaAlH}_{4}$ is as a hydrogen storage material, the maximum storage capacity of 5.5 wt. $\%$ would make it unsuitable for on-board storage, since with the additional weight and volume of the overall system the storage density for hydrogen would be too low. Therefore, alternative hydrides are intensively investigated in many laboratories. $\mathrm{Mg}\left(\mathrm{AlH}_{4}\right)_{2}$ was one of the first of such materials to be discovered and characterized [27]. However, unfortunately this compound is too unstable for practical hydrogen storage purposes and can not be rehydrogenated under the conditions of on-board storage in cars. $\mathrm{Ca}\left(\mathrm{AlH}_{4}\right)_{2}$ decomposes in a two-step reaction via a $\mathrm{CaAlH}_{5}$ intermediate with octahedral $\mathrm{AlH}_{6}$-units in a polymeric chain [28]. The second decomposition step of $\mathrm{CaAlH}_{5}$ has an enthalpy in the right range for reversibility near ambient conditions, but so far no full rehydrogenation has been achieved, in addition, the storage capacity corresponding to this step $(3 \mathrm{wt} . \%)$ is too low for practical application in cars.

Although so far no new hydride system has been discovered which shows promise as storage material in cars, the "chemical landscape" of unexplored compounds is still large. Research efforts all over the world may eventually reveal complex hydrides - be it alanates or other compounds - which are in fact suitable for on-board storage. Results with other storage materials indicate that the lessons learned with respect to the catalytic decomposition and rehydrogenation of $\mathrm{NaAlH}_{4}$ may in fact be transferable to other systems.

Above it has several times been mentioned that suitable thermodynamic properties are required for a technologically useful hydrogen storage material. In particular, this means that the equilibrium hydrogen pressure should be around $0.1 \mathrm{MPa}$ at room temperature. However, almost none of the hydrides with sufficiently high storage capacity meets this requirement. One approach for solving this problem is the addition of compounds which change the overall thermodynamics of the system. Such an additive can, for instance, be an element or a compound, which leads to the formation of more stable products, which can provide an additional enthalpic driving force. One such system which has been studied, is the $\mathrm{LiBH}_{4}$ system, which alone is much too stable for use as on-board hydrogen storage. However, with the addition of $\mathrm{MgH}_{2}$, the formation of $\mathrm{MgB}_{2}$ becomes possible, which provides an additional enthalpic contribution of $-25 \mathrm{~kJ} \mathrm{~mol}^{-1} \mathrm{H}_{2}$, thus destabilizing the $\mathrm{LiBH}_{4}$ [29] (Eq. (3)):

$$
2 \mathrm{LiBH}_{4}+\mathrm{MgH}_{2} \leftrightarrow 2 \mathrm{LiH}+\mathrm{MgB}_{2}+4 \mathrm{H}_{2} .
$$

There are numerous possibilities for such thermodynamic tailoring of potential hydrogen storage systems. However, one always has to keep in mind that the additive normally means a reduction of the specific storage densities, which may make a system, which looks attractive with respect to storage density on first sight, practically useless.

\section{Systems related to hydrides}

There are a number of systems which are related to hydrides, but which are chemically different. Most prominent among these are the amide/imide/nitride systems, where the hydrogen is part of a nitrogen containing anion. Such systems can have rather high hydrogen storage densities, if light element amides/imides/nitrides are chosen. One of the most prominent systems is the 
$\mathrm{Li}_{3} \mathrm{~N}$ system, which was (re)discovered in 2002 [30]. $\mathrm{Li}_{3} \mathrm{~N}$ can react successively with two moles of hydrogen, resulting first in the formation of $\mathrm{Li}_{2} \mathrm{NH}$, then in the formation of $\mathrm{LiNH}_{2}$ (eq. (4)):

$$
\mathrm{Li}_{3} \mathrm{~N}+2 \mathrm{H}_{2} \leftrightarrow \mathrm{Li}_{2} \mathrm{NH}+\mathrm{LiH}+\mathrm{H}_{2} \leftrightarrow \mathrm{LiNH}_{2}+2 \mathrm{LiH}
$$

The overall process corresponds to $10.4 \mathrm{wt} . \%$ storage capacity. However, the thermodynamics of this system are not favorable for on-board hydrogen storage, since an equilibrium pressure of $0.1 \mathrm{MPa}$ is only reached at temperatures around $250^{\circ} \mathrm{C}$ for the second stage (corresponding to about $6 \mathrm{wt. \% )}$ ) and even higher temperatures for the first stage. In addition, in amide/imide/nitride systems, there is always the danger of ammonia release, which - on the one hand - reduces the storage capacity upon repeated cycling (a commercially viable system has to be stable for 2000 cycles). On the other hand the ammonia would poison the membrane of the PEM fuel cell, and thus additional precautions against this have to be taken. Nevertheless, there are numerous possible systems available, in which amide/imide/nitride hydrogen shuttles exist, and thermodynamic tailoring of such compounds may in the future result in the development of a practically useful material.

\section{Reforming of liquid hydrogen carriers}

As a last technology option, the reforming of liquid hydrogen carriers shall be discussed. As can be seen from Fig. 5, the hydrocarbons have both very high gravimetric and volumetric storage densities. However, thermodynamically, they can not be dehydrogenated under any conditions relevant for on-board hydrogen storage. Even the most easily dehydrogenated systems, such as benzene/cylcohexane or toluene/methylcyclohexane, need temperatures exceeding $300{ }^{\circ} \mathrm{C}$ for full dehydrogenation, and the products of the reaction would have to be shipped back to a central plant for rehydrogenation, since this would not be possible on-board of a car. Thus, decomposition of hydrocarbons is not a viable option for on-board hydrogen generation.

Somewhat more promising, at least on first sight, appear so-called reforming reactions. Steam reforming of hydrocarbons, mostly of natural gas, is the current technology of choice for large scale hydrogen production [31] (Eq. (5)):

$$
\mathrm{C}_{\mathrm{n}} \mathrm{H}_{\mathrm{m}}+\mathrm{nH}_{2} \mathrm{O} \leftrightarrow \mathrm{nCO}+(\mathrm{n}+\mathrm{m} / 2) \mathrm{H}_{2} .
$$

Related concepts have also been studied for on-board hydrogen generation in cars [32]. This would have the tremendous advantage, that current day infrastructure based on hydrocarbons could be used also in a hydrogen economy, at least over a transition period. However, the practical obstacles for on-board hydrogen generation by reforming are also formidable. Catalytic hydrocarbon steam reforming requires temperatures exceeding $600{ }^{\circ} \mathrm{C}$, and the reformate leaving the reformer contains such high concentrations of $\mathrm{CO}$ that the fuel cell catalyst would be immediately poisoned. Thus, at least one additional shift reactor is necessary (often more than one reactor at different temperature levels) in which the catalyzed water-gas shift reaction $\left(\mathrm{CO}+\mathrm{H}_{2} \mathrm{O} \leftrightarrow \mathrm{CO}_{2}+\mathrm{H}_{2}\right)$ takes place. Even after such a shift stage, the CO levels are still too high for feeding the fuel cell, and thus a fine clean up of the gas, mostly by preferential oxidation $(\mathrm{PROX})$, is necessary, which reduces the CO concentration to a level of around $10 \mathrm{ppm}$. Thus, at least three catalytic reactors are necessary in such a fuel processor based on hydrocarbons, in addition, a sophisticated heat management involving several heat exchangers is needed for optimum performance of such systems. Especially the heat management is a big challenge, and for a fuel processor of the size necessary to supply the hydrogen to a PEM fuel cell driven car, start-up times at least on the order of several minutes are required even for the most advanced systems [33]. This and the complexity of the overall setup have induced most of the car companies to abandon the development of fuel processor systems based on hydrocarbons to supply the fuel cell with hydrogen. However, for auxiliary power units (APUs) steam reforming of hydrocarbons appears to be a viable option. Especially in the domain of leisure applications, where, for instance, camping gas is available, reforming units with a power of several hundred watt up to some kilowatt are being developed and are expected to have chances on the market [34]. 
Methanol is a hydrogen carrier the reforming of which is substantially easier than that of hydrocarbons. The reaction takes place at more moderate temperatures of $250{ }^{\circ} \mathrm{C}$ to $300{ }^{\circ} \mathrm{C}$, and the CO-concentrations in the primary reformate are much lower than in hydrocarbon reforming. Catalysts for this reaction very much resemble the methanol synthesis catalyst, which is understandable, since the primary reactions are strongly related to those found in methanol synthesis. Due to the lower complexity of methanol reforming, a prototype system based on a Mercedes, the NECAR III, has been supplied with hydrogen from a methanol steam reforming system. However, while the system did operate under practical conditions, efforts for the development of fuel processors based on methanol have largely been discontinued. This is primarily due to the fact that introduction of methanol as hydrogen carrier would require the build-up of a separate infrastructure, which would only be considered as a temporary one, since on the long run hydrogen itself is supposed to be the energy carrier of choice.

\section{Conclusions and outlook}

In addition of the approaches discussed in the preceding sections, there are many other options which are explored for hydrogen storage, such as encapsulation in glass microspheres [35] or storage in the form of hydrogen clathrate hydrates [36]. However, these are developed to an even lesser extent than the storage methods discussed above so that they do not need to be covered in more detail here. The reader is referred to the references given above for access to the literature.

From the previous discussion, it is obvious that an ideal or even just a satisfactory solution for on-board hydrogen storage in cars is still lacking. The current benchmark is the $70 \mathrm{MPa}$ high pressure storage which is the solution found in most prototype cars powered by fuel cells. The on-board reforming of liquid hydrogen carriers does not appear to have chances for large scale implementation due to the complexity of such systems. Currently, high hopes seem to be placed on sorptive storage in MOFs, but these systems have intrinsic limits which make it difficult to see a pathway to increase the hydrogen storage capacity substantially further or to achieve the presently realized storage capacities under more moderate conditions. Solid reversible storage materials, such as hydrides or amide/imide/nitride-systems presently do not meet the requirements for mobile hydrogen storage. However, in this field the widest range of parameters seems to be unexplored, as yet, and thus in this class of materials there is the highest possibility for surprising discoveries.

B. Bogdanovic (MPI Mülheim), U. Eberle (GM fuel cell activities) and M. Felderhoff (MPI Mülheim) are gratefully acknowledged for many interesting and helpful discussions on the topic of hydrogen storage. In addition, many students and post-docs have advanced our understanding of hydrides as storage systems by their research activities during the last years, and I would like to thank them for their contributions. Our research on hydrogen storage has been generously funded by GM fuel cell activities over the last ten years which is gratefully acknowledged as well.

\section{References}

1. F. Schüth, B. Bogdanovic, M. Felderhoff, Chem. Commun. 20, 2249 (2004)

2. A. Züttel, Naturwissenschaften 91, 157 (2004)

3. M. Felderhoff, C. Weidenthaler, R. von Helmholt, U. Eberle, Phys. Chem. Chem. Phys. 9, 2643 (2007)

4. U. Eberle, M. Felderhoff, F. Schüth, Angew. Chem. Int. Ed. (submitted)

5. R. von Helmholt, U. Eberle, J. Power Sources 165, 833 (2007)

6. R.S. Irani, MRS Bulletin 27, 680 (2002)

7. J. Wolf, MRS Bulletin 27, 684 (2002)

8. B. Panella, M. Hirscher, S. Roth, Carbon 43, 2209 (2005)

9. K.M. Thomas, Catal. Today 120, 389 (2007)

10. M. Dinca, J.R. Long, Angew. Chem. Int. Ed. 47, 6766 (2008) 
11. M. Eddaoudi, J. Kim, N. Rosi, D. Vodak, J. Wachter, M. O'Keefe, O.M. Yaghi, Science 295, 469 (2002)

12. A.G. Wong-Foy, A.J. Matzger, O.M. Yaghi, J. Am. Chem. Soc. 128, 3494 (2006)

13. S.K. Bhatia, A.L. Myers, Langmuir 22, 1688 (2006)

14. S.S. Han, H. Furukawa, O.M. Yaghi, W.A. Goddard III, J. Am. Chem. Soc. 130, 11580 (2008)

15. H.I. Schlesinger, H.C. Brown, A.E. Finholt, J.R. Gilbreath, H.R. Hoekstra, E.K. Hyde, J. Am. Chem. Soc. 75, 215 (1953)

16. F.H. Stephens, V. Pons, R.T. Baker, Dalton Trans., 2613 (2007)

17. B. Bogdanović, M. Schwickardi, J. Alloys Compd. 253-254, 1 (1997)

18. L. Zaluski, A. Zaluska, J.O. Ström-Olsen, J. Alloys Compd. 290, 71 (1999)

19. B. Bogdanović, M. Felderhoff, S. Kaskel, A. Pommerin, K. Schlichte, F. Schüth, Adv. Mater. 15, $1012(2003)$

20. B. Bogdanović, M. Felderhoff, A. Pommerin, F. Schüth, N. Spielkamp, Adv. Mater. 18, 1198 (2006)

21. M. Felderhoff, K. Klementiev, W. Grünert, B. Spliethoff, B. Tesche, J.M. Bellosta von Colbe, B. Bogdanović, M. Härtel, A. Pommerin, F. Schüth, C. Weidenthaler, Phys. Chem. Chem. Phys. 6, 4369 (2004)

22. J. Graetz, J.J. Reilly, J. Johnson, A.Yu. Ignatov, T.A. Tyson, Appl. Phys. Lett. 85, 500 (2004)

23. A. Léon, O. Kircher, J. Rothe, M. Fichtner, J. Phys. Chem. B. 108, 16372 (2004)

24. C.P. Balde, H.A. Stil, A.M.J. van der Eerden, K.P. de Jong, J.H. Bitter, J. Phys. Chem. C. 111, 2797 (2007)

25. J.M. Bellosta von Colbe, W. Schmidt, M. Felderhoff, B. Bogdanović, F. Schüth, Angew. Chem. Int. Ed. 45, 3663 (2006)

26. Q.J. Fu, A.J. Ramirez-Cuesta, S.C. Tsiang, J. Phys. Chem. B. 110, 711 (2006)

27. M. Fichtner, J. Engel, O. Fuhr, A. Glöss, O. Rubner, R. Ahlrichs, Inorg. Chem. 42, 7060 (2003)

28. C. Weidenthaler, T.J. Frankcombe, M. Felderhoff, Inorg. Chem. 45, 3849 (2006)

29. J.J. Vajo, S.L. Skeith, F. Mertens, J. Phys. Chem. B. 109, 3719 (2005)

30. P. Chen, Z. Xiong, J. Luo, J. Lin, K.L. Tan, Nature 420, 302 (2002)

31. J.R. Rostrup-Nielsen, Handbook of Heterogeneous Catalysis, edited by G. Ertl, H. Knözinger, F. Schüth, J. Weitkamp, $2^{\text {nd }}$ Edn. (Wiley-VCH, Weinheim, 2008), p. 2882

32. R. Peters, Handbook of Heterogeneous Catalysis, edited by G. Ertl, H. Knözinger, F. Schüth, J. Weitkamp, $2^{\text {nd }}$ Edn. (Wiley-VCH, Weinheim, 2008), p. 3045

33. C. Severin, S. Pischinger, J. Ogrezewalla, J. Power Sources 145, 675 (2005)

34. P. Beckhaus, M. Dokupil, A. Heinzel, S. Souzani, C. Spitta, J. Power Sources 145, 638 (2005)

35. D.K. Kohli, R.K. Khardekar, R. Singh, P.K. Gupta, Int. J. Hydrogen Energy 33, 417 (2008)

36. H. Lee, J. Lee, D.Y. Kim, J. Park, Y. Seo, H. Zeng, I.L. Moudrakovski, C.I. Ratcliffe, J.A. Ripmeester, Nature 434, 743 (2005) 